\title{
Management of human immunodeficiency virus in older people
}

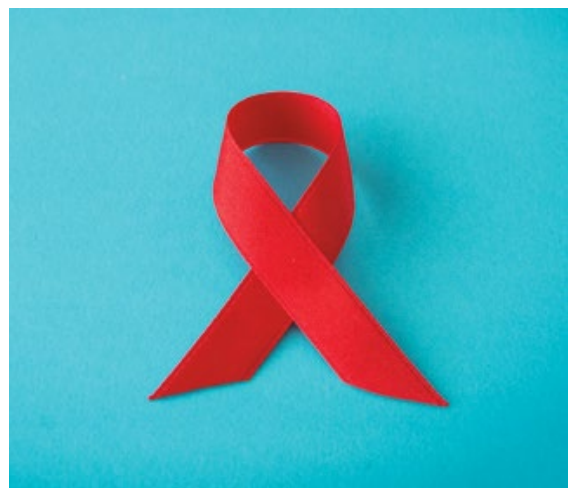

Beng Eu, Ethan Salleh, Andrew Sakko, Giovanni Guaraldi

\section{Background}

The proportion of older (aged $\geq 50$ years) people living with human immunodeficiency virus (PLHIV) within the HIV-positive population is increasing. Many comorbidities associated with ageing are observed more frequently and/or occur at an earlier age among PLHIV, compared with people who are uninfected.

\section{Objective}

The aim of this article is to improve the confidence of treating physicians who have limited HIV experience in providing care for the increasingly elderly HIV population by presenting a contemporary clinical picture of older PLHIV and discussing the key evidence-based principles of management, with reference to data in the Australian setting where applicable.

\section{Discussion}

Older PLHIV, in particular those with complex comorbidities, are likely to benefit from comprehensive multidisciplinary medical and psychosocial support as they age. Physicians are well placed to diagnose and treat HIV as early as possible in older people and ensure counselling to prevent secondary transmission of HIV.
PROJECTIONS INDICATE that the proportion of people living with human immunodeficiency virus (PLHIV) aged $\geq 50$ years is increasing and will continue to increase for at least the next decade in Western countries. ${ }^{1,2}$ Many comorbidities associated with ageing, such as cardiovascular disease, osteoporosis, malignancy, metabolic disorders and renal disease, occur more frequently and/or at an earlier age in PLHIV than in people who are uninfected..$^{3-5}$ Treating physicians with limited HIV experience are generally expert in early identification, prevention and management of age-associated comorbidities in the general population, and are therefore well placed to manage and care for older PLHIV.

\section{HIV prevalence in older people}

In 2017 there were an estimated 27,545 PLHIV, including a total of 963 cases of newly diagnosed HIV, in Australia. ${ }^{6}$ The majority were in the exposure category of men who have sex with men (MSM) at the time of diagnosis. ${ }^{6}$ At present, approximately $46 \%$ of PLHIV in Australia are aged $\geq 50$ years. ${ }^{6}$ An increase in diagnoses in older people, as well as an increase in the life expectancy of PLHIV taking antiretroviral therapy (ART), are contributing to an increasingly aged population of PLHIV and consequently a unique presentation of age-related comorbidities that require clinical management. ${ }^{7,8}$

\section{Age-related comorbidities in older people living with HIV} PLHIV have an increased risk of age-associated comorbidities, compared with individuals of the same age in the general population. ${ }^{2-4}$ Factors associated with these comorbidities in PLHIV include a lower nadir CD4 cell count, prolonged ART exposure, persistent inflammation secondary to chronic viral activation and various lifestyle risk factors. ${ }^{3,9} \mathrm{~A}$ decreased immunological response due to increasing age in PLHIV can also occur; this typically manifests as a poor response to vaccination, an increased susceptibility to infection and/or an increased risk of other comorbidities. ${ }^{10,11}$ In addition, older people with a long history of ART may have medication-associated morbidities from older or experimental agents used in the past. ${ }^{12}$ Neurocognitive conditions associated with HIV, including HIV-associated dementia and HIV-associated neurocognitive impairment, are of particular ongoing concern as little is known regarding their progression and management, and they 
may result in sub-optimal adherence to treatment and treatment failure. Some cancers have a risk of earlier onset in PLHIV and, while the incidence of Kaposi sarcoma and non-Hodgkin lymphoma is decreasing for PLHIV, the risk of anal, liver and colorectal cancer is increasing. ${ }^{13}$ The key characteristics of comorbidities commonly associated with ageing in PLHIV compared with people who are uninfected are summarised in Table 1.

Multimorbidity, which commonly refers to the coexistence of two or more clinically manifest chronic diseases, ${ }^{14}$ is also more prevalent in PLHIV than in people who are uninfected. ${ }^{15,16}$ Some older PLHIV are newly diagnosed, whereas others have lived with HIV for a long time and may have been treated long term with ART and/or previously diagnosed with one or more acquired immune deficiency syndrome (AIDS)-defining conditions. This is important to note, as older people with a longer duration of HIV infection have a higher probability of multimorbidity than PLHIV who seroconvert at older ages. ${ }^{15}$ Therefore, similar to people who are uninfected, the development of age-related comorbidities and multimorbidity for PLHIV likely involve heterogeneous processes. Multimorbidity is of particular concern as it can contribute to frailty and therefore add to vulnerability and complexity in clinical management. ${ }^{4,16}$ In fact, emerging evidence indicates that assessment of PLHIV using a frailty index can predict survival and multimorbidity, ${ }^{17}$ highlighting the potential negative consequences of frailty in older PLHIV.

\section{Clinical management of older people living with HIV} ART is recommended for all PLHIV, including older people, and early treatment initiation is particularly important for older people because of their potentially blunted response to ART and increased risk of serious non-AIDS events. ${ }^{18}$ ART suppresses plasma viraemia, which decreases the risk of drug-resistant mutations, preserves or improves CD4 cell numbers and confers considerable morbidity and mortality benefits. As a result, life-expectancy in people with HIV is now approaching that of the general population. ${ }^{19}$

However, some ART medications can also exacerbate age-related comorbidities (Table 2). As a consequence of these potential toxicities, it is important to employ a proactive approach to ART management in older PLHIV. ART choice should ideally be based on management of comorbidities, multimorbidity,

\section{Table 1. Age-related comorbidities in people living with HIV}

\begin{tabular}{|c|c|}
\hline \multicolumn{2}{|l|}{ Comorbidities } \\
\hline Acute myocardial infarction & $\begin{array}{l}\text { - Up to } 50 \% \text { increased risk of acute myocardial infarction } \\
\text { - Leading cause of death in PLHIV on effective ART }\end{array}$ \\
\hline Bone disease & $\begin{array}{l}\text { - Six-fold increase in low BMD }{ }^{34} \\
\text { - Four-fold increase in osteoporosis risk }{ }^{35}\end{array}$ \\
\hline End-stage liver disease & $\begin{array}{l}\text { - Progression to end-stage liver disease more rapid with } \\
\text { HBV/HIV coinfection than with HBV monoinfection }{ }^{18} \\
\text { - Three-fold greater risk of decompensated liver disease } \\
\text { with HCV/HIV coinfection than with HCV monoinfection }{ }^{18}\end{array}$ \\
\hline End-stage renal disease & $\begin{array}{l}\text { - Earlier diagnosis of end-stage renal disease }{ }^{5} \\
\text { - TDF and other comorbidities can increase risk }{ }^{11}\end{array}$ \\
\hline HAND & $\begin{array}{l}\text { - More than } 50 \% \text { of PLHIV have some neurocognitive } \\
\text { impairment }{ }^{36} \\
\text { - } 2-8 \% \text { of PLHIV have HIV-associated dementia }{ }^{37} \\
\text { - HAND and HIV-associated dementia may contribute to } \\
\text { treatment failures }\end{array}$ \\
\hline Mental health conditions & $\begin{array}{l}\text { - } 20-40 \% \text { of PLHIV compared with } 7 \% \text { of the general } \\
\text { population report depression }{ }^{28}\end{array}$ \\
\hline Non-AIDS defining cancer & $\begin{array}{l}\text { - Increased risk of lung, anal and liver cancer and Hodgkin } \\
\text { lymphoma }{ }^{13} \\
\text { - Melanoma is common in Australian PLHIV }{ }^{38}\end{array}$ \\
\hline Type 2 diabetes mellitus & $\begin{array}{l}\text { - } 4 \% \text { higher prevalence }{ }^{39} \\
\text { - More likely to develop at younger ages and in the absence } \\
\text { of obesity } \\
\text { - Increasing age, HCV coinfection and increasing BMI have } \\
\text { a more pronounced effect on the risk of type } 2 \text { diabetes } \\
\text { mellitus }^{40}\end{array}$ \\
\hline \multicolumn{2}{|l|}{ Geriatric syndromes } \\
\hline Delirium & $\begin{array}{l}\text { - Delirium can occur in young adults and children } \\
\text { with HIV } 41,42\end{array}$ \\
\hline Falls & - Fall rate increased in PLHIV43 \\
\hline Frailty & $\begin{array}{l}\text { - Increased risk of pre-frailty and frailty }{ }^{32,44} \\
\text { - Occurs in } 11-23 \% \text { of Australian PLHIV } \\
\end{array}$ \\
\hline $\begin{array}{l}\text { Functional impairment and } \\
\text { disability }\end{array}$ & $\begin{array}{l}\text { Increased risk of functional impairment and disability, } \\
\text { including difficulty with mobility, self-care and activities } \\
\text { of daily living }{ }^{45}\end{array}$ \\
\hline Hearing and visual loss & $\begin{array}{l}\text { - Poorer lower-frequency and higher-frequency hearing } \\
\text { - Vision function abnormalities are common in people } \\
\text { with AIDS }\end{array}$ \\
\hline Urinary incontinence & - Increased incidence of urinary continence in PLHIV48 \\
\hline
\end{tabular}

AIDS, acquired immune deficiency syndrome; $A R T$, antiretroviral therapy; $B M D$, bone mineral density; $B M I$, body mass index; HIV, human immunodeficiency virus; HAND, HIV-associated neurocognitive impairment; $H B V$, hepatitis $B$ virus; $H C V$, hepatitis $C$ virus; $N A D C$, non-AIDS defining cancer; $P L H I V$, people living with HIV; TDF, tenofovir disoproxil fumarate 
polypharmacy and frailty, in addition to virological suppression. A complete treatment history is important, and HIV section 100 prescribers should be consulted to review ART regimens and, if clinically appropriate, modify regimens to include safer agents as part of the management of comorbidities. For example, changing from a regimen containing tenofovir disoproxil fumarate to a regimen containing tenofovir alafenamide can result in significant improvements in glomerular function and spine and hip bone mineral densities. ${ }^{20}$ Changing to a two-medication regimen, such as dolutegravir/rilpivirine, ${ }^{21-23}$ is another possible treatment strategy that may be used to avoid toxicities, although any decision to simplify a treatment regimen should be considered in consultation with an HIV section 100 prescriber.

ART regimens with a high genetic barrier to resistance, such as those containing an agent from the integrase inhibitor class, for example dolutegravir or bictegravir, ${ }^{24-26}$ or protease inhibitor class, are particularly important for older PLHIV.

\section{Table 2. Selected age-related comorbidities that may be exacerbated by, or associated with, antiretroviral agents}

\begin{tabular}{|c|c|}
\hline Comorbidity & Antiretroviral agent effects \\
\hline Bone disease & $\begin{array}{l}\text { - Tenofovir disoproxil fumarate: low BMD and } \\
\text { osteoporotic fracture }{ }^{49}\end{array}$ \\
\hline Cardiovascular disease & $\begin{array}{l}\text { - Abacavir: MI50 } \\
\text { - Darunavir:* CVD } 51\end{array}$ \\
\hline Diabetes mellitus & $\begin{array}{l}\text { - Zidovudine, stavudine, didanosine, lopinavir, } \\
\text { nelfinavir and indinavir }{ }^{52}\end{array}$ \\
\hline Neurocognitive impairment & $\begin{array}{l}\text { - Efavirenz: nervous system side effects and impaired } \\
\text { neurocognitive functioning } \\
\text { - Dolutegravir: neuropsychiatric side effects including } \\
\text { insomnia and sleep disturbance }{ }^{54}\end{array}$ \\
\hline Renal disease & $\begin{array}{l}\text { - Adefovir: }{ }^{\dagger} \text { proximal renal tubular dysfunction }{ }^{55} \\
\text { - Atazanavir: kidney stones } \\
\text { - Indinavir: CKD and renal stones }{ }^{57,58} \\
\text { - Tenofovir disoproxil fumarate: } C K D^{59}\end{array}$ \\
\hline \multicolumn{2}{|c|}{$\begin{array}{l}\text { *While darunavir has been shown to be associated with increased CVD risk, atazanavir has not, } \\
\text { suggesting that protease inhibitors as a class may not be associated with an increased CVD risk. } \\
\text { 'Adefovir was used during HIV clinical trials in Australia but rarely outside of the clinical trial setting. } \\
\text { BMD, bone mineral density; CKD, chronic kidney disease; CVD, cardiovascular disease; HIV, human } \\
\text { immunodeficiency virus; MI, myocardial infarction }\end{array}$} \\
\hline
\end{tabular}

Evidence-based approaches to management of common individual comorbidities in PLHIV are summarised in Table 3. PLHIV benefit from the same age-appropriate health assessments as those for the general population. The Royal Australian College of General Practitioners' Guidelines for preventive activities in general practice, 9th edition (www.racgp.org.au/your-practice/ guidelines/redbook) is therefore an appropriate guide when manageing older PLHIV, in particular when screening for bowel, skin and anal cancer. Anal cancer in MSM is a particularly important issue, and an Australian study has shown that regular digital anorectal examinations for MSM aged $\geq 50$ years is cost effective and may detect anal cancer earlier. ${ }^{27}$ The Australian Society for HIV, Viral Hepatitis and Sexual Health Medicine (ASHM) also offers helpful resources for HIV management, including specific recommendations for older PLHIV (www.ashm.org.au/HIV/ hiv-management).

Screening for comorbidities should ideally include the collection of modifiable and non-modifiable risk factors, estimation of risk probability using appropriate
*While darunavir has been shown to be associated with increased CVD risk, atazanavir has not, immunodeficiency virus; MI, myocardial infarction algorithms and evaluation using markers of subclinical disease. Furthermore, duration of ART should be taken into account when considering surveillance of disease risk, frequency of follow-up, intensity of care and choice of therapy. ${ }^{15}$

When manageing comorbidities in older PLHIV, it is important that patients adhere to ART so that HIV viral load remains undetectable. Physicians are well placed to treat risk factors for existing comorbidities and empower PLHIV to make lifestyle changes. ${ }^{28}$ The benefits of ceasing use of tobacco, alcohol and other drugs should either be delivered repeatedly where appropriate, or continued abstinence encouraged. ${ }^{28}$ Adherence to ART should also be assessed, ideally every three to six months, and factors that may decrease adherence, such as complicated regimens, unnecessary concomitant medications and neurocognitive deficits, should be identified and managed. ${ }^{28}$

Polypharmacy is particularly common in older PLHIV, ${ }^{18}$ leading to a greater risk of drug-drug interactions (DDIs) between ART agents and concomitant medications; consequently, there is an increased risk of non-adherence, cognitive impairment, impaired balance, falls and hospitalisation. ${ }^{28}$ It is important that physicians periodically review the potential for DDIs with ART, particularly when starting or changing concomitant non-HIV medications. ${ }^{18}$ Furthermore, physicians should routinely check for potentially inappropriate medication prescriptions, particularly in older PLHIV. The University of Liverpool HIV drug interaction checker (www.hiv-druginteractions.org) is a particularly useful tool to assess the potential for DDIs. ${ }^{29}$ A recent Australian study showed that medication reviews by HIV specialist pharmacists within the general practice setting may help identify, prevent and/or resolve DDIs and other medication-related problems in PLHIV. ${ }^{30}$

\section{The future of HIV care: A multidimensional approach} Frailty can predispose individuals to increased risks of multimorbidity and mortality. ${ }^{11} \mathrm{HIV}$ infection increases 
frailty risk, ${ }^{31}$ and a recent study estimated frailty to occur in $11-23 \%$ of PLHIV in one Australian cohort. ${ }^{32}$ It is particularly important to identify and manage frailty because frailty can lead to or exacerbate disability. While frailty can be reversed, disability cannot. However, a lack of consensus remains on the defining criteria for diagnosis of frailty, and treatment of frailty can be complex, with no evidencebased strategies yet developed. ${ }^{31}$

To effectively manage ageing as a whole, the future of care for PLHIV will likely require a shift from the traditional interdisciplinary approach to a comprehensive 'geriatric-type' multidimensional, multidisciplinary assessment aimed at evaluating a combination of medical, psychosocial and functional capabilities and limitations. ${ }^{28}$ Diverse consultation approaches that are built into individualised management plans, and focus on quality of life and prevention of disability, are likely to be of benefit. The increasing proportion of older PLHIV who have comorbidities, multimorbidity and/or frailty also suggests an evolving geriatric-HIV scenario in which evidence-based screening, monitoring and treatment guidelines will almost certainly be of value to ensure high-quality care.

In the meantime, current guidelines recommend that HIV experts, primary care providers and other specialists work together to optimise care for older PLHIV, particularly those with complex comorbidities. ${ }^{18}$ Early HIV diagnosis in older people can be facilitated by enquiring in a non-judgemental manner about risk factors for HIV, including sexual history and intravenous drug use, and regularly testing those at risk. Counselling remains important to prevent secondary transmission of HIV. Older people are also likely to benefit from comprehensive multidisciplinary medical and psychosocial support to help them age as successfully as possible with HIV.

\section{Conclusions}

As a result of the ageing HIV population, comorbidities, multimorbidity and frailty will increasingly become a major focus of care. Continued research into ageing in older PLHIV is required for the management, and perhaps prevention, of comorbidities, multimorbidity and frailty, and may form the basis of a new model for manageing ageing in the general population.

\section{Authors}

Beng Eu MBBS, GDFM, General Practitioner, S100 Prescriber and Director, Prahran Market Clinic, Prahran, Vic

\section{Table 3. Overview of key aspects to management of common individual comorbidities in older people living with HIV*}

\begin{tabular}{ll}
\hline Comorbidity & Key management aspects \\
\hline Bone disease & - Consider DEXA for those with risk factors ${ }^{28}$ \\
& - Address fall risk and ensure sufficient dietary calcium and vitamin $D^{28}$ \\
- Refer complicated cases to an osteoporosis specialist ${ }^{28}$ & - Replace TDF with TAF ${ }^{18} \neq \$$ \\
\hline Cardiovascular disease & - Assess risk with D:A:D score ${ }^{60}$ or Framingham score every 2 years in all men aged $>40$ years and \\
& women aged $>50$ years without CVD \\
& - Use ABC with caution in cases of high CVD risk $(>20 \%)^{18} \neq \$$ \\
- Reduce all modifiable risk factors, particularly blood pressure, glucose and lipids ${ }^{28}$
\end{tabular}

Neurocognitive impairment $\quad$ - Neuropsychological evaluation ${ }^{28}$

- Neurological examination, brain MRI and CSF examination ${ }^{28}$

- Address adverse lifestyle habits and encourage adherence to ART if needed ${ }^{28}$

- Avoid EFV, particularly in patients with mental illness 28 ‡\$

Renal disease

- Annual assessment for risk factors of CKD, or more frequently as indicated ${ }^{28} \|$

- Adjust ART dose or modify ART regimen ${ }^{28}$ £

- Replace TDF with TAF ${ }^{28}$ ₹s

- Refer to nephrologist if new CKD or progressive decline in eGFR ${ }^{28}$

*This table summarises the management of individual comorbidities only, and not aging, which includes multimorbidity, frailty and disability. While there is a plethora of evidence-based guidance for the management of individual comorbidities in HIV, little is currently known about achievement of successful ageing with HIV, which consequently remains major clinical challenge.

${ }^{+} D E X A$ is not funded for all patients by the Medicare Benefits Schedule in Australia.

¥To avoid drug-drug interactions with HIV medications, always consult the University of Liverpool HIV drug interaction checker before prescribing new medications (www.hiv-druginteractions.org)

s/n Australia, refer to an HIV section 100 prescriber to review and reactively or pre-emptively switch ART when appropriate.

"More frequent monitoring is required if eGFR $<90 \mathrm{~mL} / \mathrm{min}, C K D$ risk factors present and/or prior to starting and treatment with nephrotoxic drugs.

$A B C$, abacavir; $A R T$, antiretroviral therapy; $C K D$, chronic kidney disease; $C S F$, cerebrospinal fluid; $C V D$, cardiovascular disease; $D: A: D$, data collection on adverse events of anti-HIV drugs; DEXA, dual-energy X-ray absorptiometry; eGFR, estimated glomerular filtration rate; EFV, efavirenz; MRI, magnetic resonance imaging; $T A F$, tenofovir alafenamide; TDF, tenofovir disoproxil fumarate 
Ethan Salleh MBBS, FRACGP, General Practitioner and S100 Prescriber, Gladstone Road Medical Centre, Highgate Hill, Qld

Andrew Sakko PhD, CMPP, Medical Writer, i Write Medical, Bright, Vic

Giovanni Guaraldi MD, Associate Professor, Department of Medical and Surgical Sciences for Children and Adults, University of Modena and Reggio Emilia, Modena, Italy.giovanni.guaraldi@ unimore.it

Competing interests: BE, ES and GG report nonfinancial support from Gilead Sciences during the preparation of this manuscript. AS reports personal fees from Gilead Sciences during the preparation of the manuscript, and personal fees from Syneos Health, Research Review, ViiV Healthcare and inVentiv Health outside the submitted work.

Funding: Support for manuscript preparation was funded by Gilead Sciences. The authors had full access to all relevant data, and Gilead Sciences had no involvement in data analysis and interpretation, or in the concept or writing of the manuscript. Provenance and peer review: Not commissioned, externally peer reviewed.

\section{References}

1. CDC Centers for Disease Control and Prevention HIV among people aged 50 and older. Atlanta: CDC Centers for Disease Control and Prevention updated 2018. Available at www.cdc.gov/hiv/ group/age/olderamericans/index.html [Accessed 30 July 2018]

2. Smit M, Brinkman K, Geerlings $S$, et al. Future challenges for clinical care of an ageing population infected with HIV: A modelling study. Lancet Infect Dis 2015;15(7):810-18. doi: 10.1016/S14733099(15)00056-0.

3. Guaraldi G, Orlando G, Zona S, et al. Premature age-related comorbidities among HIV-infected persons compared with the general population. Clin Infect Dis 2011;53(11):1120-26. doi: 10.1093/ cid/cir627.

4. Schouten J, Wit FW, Stolte IG, et al. Cross-sectional comparison of the prevalence of age-associated comorbidities and their risk factors between HIV-infected and uninfected individuals: The AGEhIV cohort study. Clin Infect Dis 2014;59(12):1787-97. doi: 10.1093/cid/ ciu701.

5. Althoff KN, McGinnis KA, Wyatt CM, et al. Comparison of risk and age at diagnosis of myocardial infarction, end-stage renal disease, and non-AIDS-defining cancer in HIV-infected versus uninfected adults. Clin Infect Dis 2015;60(4):627-38. doi: 10.1093/cid/ciu869.

6. The Kirby Institute. HIV, viral hepatitis and sexually transmissible infections in Australia: Annual surveillance report 2018. Sydney: University of New South Wales, 2017. Available at https://kirby. unsw.edu.au/sites/default/files/kirby/report/KI Annual-Surveillance-Report-2018.pdf [Accessed 30 May 2019].

7. May M, Gompels M, Delpech V, et al. Impact of late diagnosis and treatment on life expectancy in people with HIV-1: UK collaborative HIV cohort (UK CHIC) study. BMJ 2011;343:d6016. doi: 10.1136/bmj.d6016.

8. Guaraldi G, Cossarizza A, Franceschi C, et al. Life expectancy in the immune recovery era: The evolving scenario of the HIV epidemic in northern Italy. J Acquir Immune Defic Syndr 2014;65(2):175-81. doi: 10.1097/ QAI.0000000000000018.

9. Deeks SG, Phillips AN. HIV infection, antiretroviral treatment, ageing, and non-AIDS related morbidity. BMJ 2009;338:a3172. doi: 10.1136/bmj.a3172.
10. Althoff KN, Justice AC, Gange SJ, et al. Virologic and immunologic response to HAART, by age and regimen class. AIDS 2010;24(16):2469-79. doi: 10.1097/QAD.0b013e32833e6d14.

11. Escota GV, O'Halloran JA, Powderly WG, Presti RM. Understanding mechanisms to promote successful ageing in persons living with HIV. Int J Infect Dis 2018;66:56-64. doi: 10.1016/j. ijid.2017.11.010.

12. Guaraldi G, Prakash M, Moecklinghoff C Stellbrink HJ. Morbidity in older HIV-infected patients: Impact of long-term antiretroviral use. AIDS Rev 2014;16(2):75-89.

13. Silverberg MJ, Lau B, Achenbach CJ, et al. Cumulative incidence of cancer among persons with HIV in North America: A cohort study. Ann Intern Med 2015;163(7):507-18. doi: 10.7326/ M14-2768.

14. Villacampa-Fernández P, Navarro-Pardo E, Tarin Jر J Cano A. Frailty and multimorbidity: Two related yet different concepts. Maturitas 2017;95:31-35. doi: 10.1016/j.maturitas.2016.10.008.

15. Guaraldi G, Zona S, Brothers TD, et al. Ageing with HIV vs. HIV seroconversion at older age: A diverse population with distinct comorbidity profiles. PLoS One 2015;10(4):e0118531. doi: 10.1371/journal. pone. 0118531 .

16. Guaraldi G, Silva AR, Stentarelli C. Multimorbidity and functional status assessment. Curr Opin HIV AIDS 2014;9(4):386-97. doi: 10.1097/ COH.0000000000000079.

17. Guaraldi G, Brothers TD, Zona S, et al. A frailty index predicts survival and incident multimorbidity independent of markers of HIV disease severity. AIDS 2015:29(13):1633-41. doi: 10.1097/ QAD.0000000000000753.

18. Panel on Antiretroviral Guidelines for Adults and Adolescents. Guidelines for the use of antiretroviral agents in adults and adolescents living with HIV. Canberra: DHHS, 2018. Available at www.aidsinfo. nih.gov/ContentFiles/AdultandAdolescentGL.pdf [Accessed 30 July 2018].

19. Wandeler G, Johnson LF, Egger M. Trends in life expectancy of HIV-positive adults on antiretroviral therapy across the globe: Comparisons with general population. Curr Opin HIV AIDS 2016;11(5):492-500. doi: 10.1097/ COH.0000000000000298.

20. Mills A, Arribas JR, Andrade-Villanueva J, et al. Switching from tenofovir disoproxil fumarate to tenofovir alafenamide in antiretroviral regimens for virologically suppressed adults with HIV-1 infection: A randomised, active-controlled, multicentre, open-label, phase 3, non-inferiority study. Lancet Infect Dis 2016;16(1):43-52. doi: 10.1016/S1473-3099(15)00348-5.

21. Llibre JM, Hung C-C, Brinson $C$, et al. Phase III SWORD 1\&2: Switch to DTG+RPV maintains virologic suppression through 48 wks. Conference on retroviruses and opportunistic infections, Seattle, WA, USA, 13-16 February 2017. Abstract 44LB.

22. Taiwo BO, Zheng L, Stefanescu A, et al. ACTG A5353: A pilot study of dolutegravir plus lamivudine for initial treatment of Human Immunodeficiency Virus-1 (HIV-1)-infected participants with HIV-1 RNA <500000 copies/mL. Clin Infect Dis 2018;66(11):1689-97. doi: 10.1093/ cid/cix1083.

23. Margolis DA, Gonzalez-Garcia J, Stellbrink HJ, et al. Long-acting intramuscular cabotegravir and rilpivirine in adults with HIV-1 infection (LATTE-2): 96-week results of a randomised, open-label, phase $2 \mathrm{~b}$, non-inferiority trial. Lancet 2017;390(10101):1499-1510. doi: 10.1016/S01406736(17)31917-7.
24. Llibre JM, Pulido F, García F, García Deltoro M Blanco JL, Delgado R. Genetic barrier to resistance for dolutegravir. AIDS Rev 2015;17(1):56-64.

25. Gallant J, Lazzarin A, Mills A, et al. Bictegravir, emtricitabine, and tenofovir alafenamide versus dolutegravir, abacavir, and lamivudine for initial treatment of HIV-1 infection (GS-US-3801489): A double-blind, multicentre, phase 3 , randomised controlled non-inferiority trial. Lancet 2017;390(10107):2063-72. doi: 10.1016/S01406736(17)32299-7.

26. Sax PE, Pozniak A, Montes ML, et al. Coformulated bictegravir, emtricitabine, and tenofovir alafenamide versus dolutegravir with emtricitabine and tenofovir alafenamide, for initial treatment of HIV-1 infection (GS-US-380-1490): A randomised, double-blind, multicentre, phase 3, non-inferiority trial. Lancet 2017;390(10107):2073-82. doi: 10.1016/S01406736(17)32340-1.

27. Ong JJ, Fairley CK, Carroll S, et al. Costeffectiveness of screening for anal cancer using regular digital ano-rectal examinations in men who have sex with men living with HIV. J Int AIDS Soc 2016;19(1):20514. doi: 10.7448/IAS.19.1.20514.

28. European AIDS Clinical Society. Guidelines, October 2017, Version 9.0. Belgium: EACS, 2017. Available at www.eacsociety.org/files/ guidelines_9.0-english.pdf [Accessed 30 July 2018].

29. University of Liverpool, HIV Drug Interactions. HIV drug interaction checker. Liverpool: University of Liverpool, updated 2018. Available at www.hivdruginteractions.org [Accessed 30 July 2018].

30. Mackie K, Duncan A, Poole S, et al. Pharmacist review of medications for HIV-positive people seen in general practice (PROM-GP). 16th European AIDS Conference, 25-27 October 2017, Milan, Italy. Poster PE11/20.

31. Willig AL, Overton ET, Saag MS. The silent epidemic - Frailty and ageing with HIV. Total Patient Care HIV HCV 2016;1(1):6-17.

32. Yeoh HL, Cheng A, Palmer C, Crowe SM, Hoy JF. Frailty in men living with HIV: A cross-sectional comparison of three frailty instruments. Antivir Ther 2018;23(2):117-27. doi: 10.3851/IMP3185.

33. Rodger AJ, Lodwick R, Schechter M, et al. Mortality in well controlled HIV in the continuous antiretroviral therapy arms of the SMART and ESPRIT trials compared with the general population. AIDS 2013;27(6):973-79. doi: 10.1097/ QAD.0b013e32835cae9c.

34. Kooij KW, Wit FW, Bisschop PH, et al. Low bone mineral density in patients with well-suppressed HIV infection: Association with body weight, smoking, and prior advanced HIV disease. J Infect Dis 2015;211(4):539-48. doi: 10.1093/infdis/jiu499.

35. Brown TT, Qaqish RB. Antiretroviral therapy and the prevalence of osteopenia and osteoporosis: A meta-analytic review. AIDS 2006;20(17):2165-74. doi: 10.1097/QAD.0b013e32801022eb.

36. Clifford DB. HIV-associated neurocognitive disorder. Curr Opin Infect Dis 2017;30(1):117-22. doi: 10.1097/QC0.0000000000000328.

37. Saylor D, Dickens AM, Sacktor N, et al. HIVassociated neurocognitive disorder - Pathogenesis and prospects for treatment. Nat Rev Neurol 2016;12(4):234-48. doi: 10.1038/nrneurol.2016.27.

38. Petoumenos K, van Leuwen MT, Vajdic CM, et al. Cancer, immunodeficiency and antiretroviral treatment: Results from the Australian HIV Observational Database (AHOD). HIV Med 2013;14(2):77-84. doi: 10.1111/j.14681293.2012.01038.x. 
39. Hernandez-Romieu AC, Garg S, Rosenberg ES, Thompson-Paul AM, Skarbinski J. Is diabetes prevalence higher among HIV-infected individuals compared with the general population? Evidence from MMP and NHANES 2009-2010. BMJ Open Diabetes Res Care 2017;5(1):e000304. doi: 10.1136/bmjdrc-2016-000304.

40. Butt AA, McGinnis K, Rodriguez-Barradas MC, et al. HIV infection and the risk of diabetes mellitus. AIDS 2009;23(10):1227-34. doi: 10.1097/ QAD.0b013e32832bd7af.

41. Singer EJ, Thames AD. Neurobehavioral manifestations of human immunodeficiency virus/AIDS: Diagnosis and treatment. Neurol Clin 2016;34(1):33-53. doi: 10.1016/j. ncl.2015.08.003.

42. Hatherill S, Flisher A. Delirium in children with HIV/AIDS. J Child Neurol 2009;24(7):879-83. doi: 10.1177/0883073809332399.

43. Erlandson KM, Allshouse AA, Jankowski CM, et al. Risk factors for falls in HIV-infected persons. J Acquir Immune Defic Syndr 2012;61(4):484-89. doi: 10.1097/QAl.0b013e3182716e38.

44. Kooij KW, Wit FW, Schouten J, et al. HIV infection is independently associated with frailty in middle-aged HIV type 1-infected individuals compared with similar but uninfected controls. AIDS 2016;30(2):241-50. doi: 10.1097/ QAD.0000000000000910.

45. Erlandson KM, Schrack JA, Jankowski CM, Brown TT, Campbell TB. Functional impairment, disability, and frailty in adults ageing with HIVinfection. Curr HIV/AIDS Rep 2014;11(3):279-90. doi: 10.1007/s11904-014-0215-y.

46. Torre P 3rd, Hoffman HJ, Springer G, et al. Hearing loss among HIV-seropositive and HIVseronegative men and women. JAMA Otolaryngol Head Neck Surg 2015;141(3):202-10. doi: 10.1001/ jamaoto.2014.3302.

47. Freeman WR, Van Natta ML, Jabs D, et al. Vision function in HIV-infected individuals without retinitis: Report of the studies of ocular complications of AIDS research group. Am J Ophthalmol 2008;145(3):453-62. doi: 10.1016/j. ajo.2007.10.013.

48. Greene M, Covinsky KE, Valcour V, et al Geriatric syndromes in older HIV-infected adults. J Acquir Immune Defic Syndr 2015;69(2):161-67. doi: 10.1097/QAI.0000000000000556.

49. Moran CA, Weitzmann MN, Ofotokun I. Bone loss in HIV infection. Curr Treat Options Infect Dis 2017;9(1):52-67. doi: 10.1007/s40506-017-0109-9.

50. Strategies for Management of Anti-Retrovira Therapy/INSIGHT1; DAD Study Groups. Use of nucleoside reverse transcriptase inhibitors and risk of myocardial infarction in HIV-infected patients. AIDS 2008;22(14):F17-24. doi: 10.1097/ QAD.0b013e32830fe35e.

51. Lundgren J, Mocroft A, Ryom L. Contemporary protease inhibitors and cardiovascular risk. Curr Opin Infect Dis 2018:31(1):8-13. doi: 10.1097/ QC0.0000000000000425.

52. Samad F, Harris M, Puskas CM, et al. Incidence of diabetes mellitus and factors associated with its development in HIV-positive patients over the age of 50. BMJ Open Diabetes Res Care 2017;5(1):e000457. doi: 10.1136/bmjdrc-2017000457

53. Ma Q, Vaida F, Wong J, et al. Long-term efavirenz use is associated with worse neurocognitive functioning in HIV-infected patients. J Neurovirol 2016;22(2):170-78. doi: 10.1007/s13365-015-0382-7.

54. Hoffmann C, Welz T, Sabranski M, et al. Higher rates of neuropsychiatric adverse events leading to dolutegravir discontinuation in women and older patients. HIV Med 2017;18(1):56-63. doi: 10.1111/hiv.12468.
55. Fisher EJ, Chaloner K, Cohn DL, et al. The safety and efficacy of adefovir dipivoxil in patients with advanced HIV disease: A randomized, placebocontrolled trial. AIDS 2001;15(13):1695-700.

56. Rockwood N, Mandalia S, Bower M, Gazzard B, Nelson M. Ritonavir-boosted atazanavir exposure is associated with an increased rate of renal stones compared with efavirenz, ritonavir-boosted lopinavir and ritonavir-boosted darunavir. AIDS 2011;25(13):1671-73. doi: 10.1097/ QAD.0b013e32834a1cd6.

57. Mocroft A, Kirk O, Reiss $P$, et al. Estimated glomerular filtration rate, chronic kidney disease and antiretroviral drug use in HIV-positive patients. AIDS 2010;24(11):1667-78. doi: 10.1097/ QAD.0b013e328339fe53.

58. Kohan AD, Armenakas NA, Fracchia JA. Indinavir urolithiasis: An emerging cause of renal colic in patients with human immunodeficiency virus. J Urol 1999:161(6):1765-68.

59. Achhra AC, Nugent M, Mocroft A, Ryom L, Wyatt CM. Chronic kidney disease and antiretroviral therapy in HIV-positive individuals: Recent developments. Curr HIV/AIDS Rep 2016;13(3):149-57. doi: 10.1007/s11904-016-0315-y.

60. Markowicz S, Delforge M, Necsoi C, De Wit S. Cardiovascular risk evaluation of HIV-positive patients in a case-control study: Comparison of the D:A:D and Framingham equations. J Int AIDS Soc 2014;17(4 Suppl 3):19515. doi: 10.7448/ IAS.17.4.19515. 